\title{
‡USGS
}

\section{Mapping Benefits from Updated Ifsar Data in Alaska- Improved Source Data Enables Better Maps}

New, larger scale, higher resolution digital topographic maps for Alaska are key derived products from interferometric synthetic aperture radar (ifsar) data and other improved source data such as SPOT imagery.

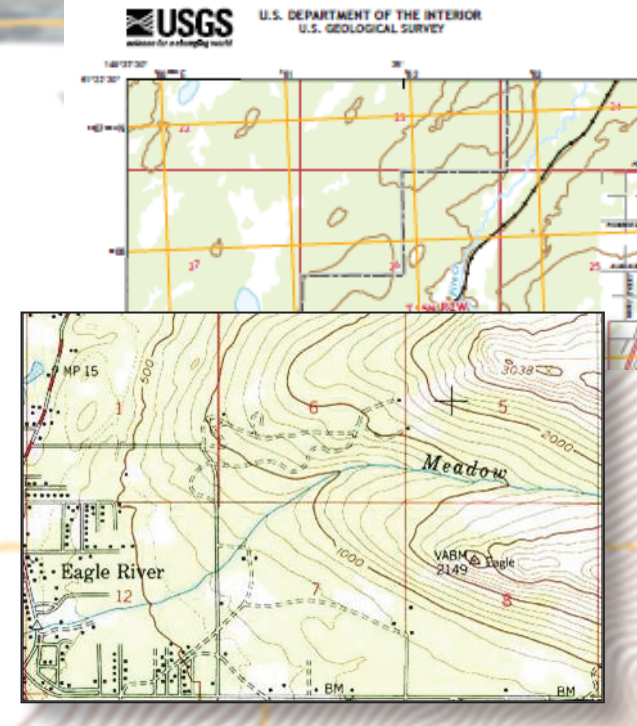

U.S. Geological Survey map published in 1960 at $1: 63,360$.
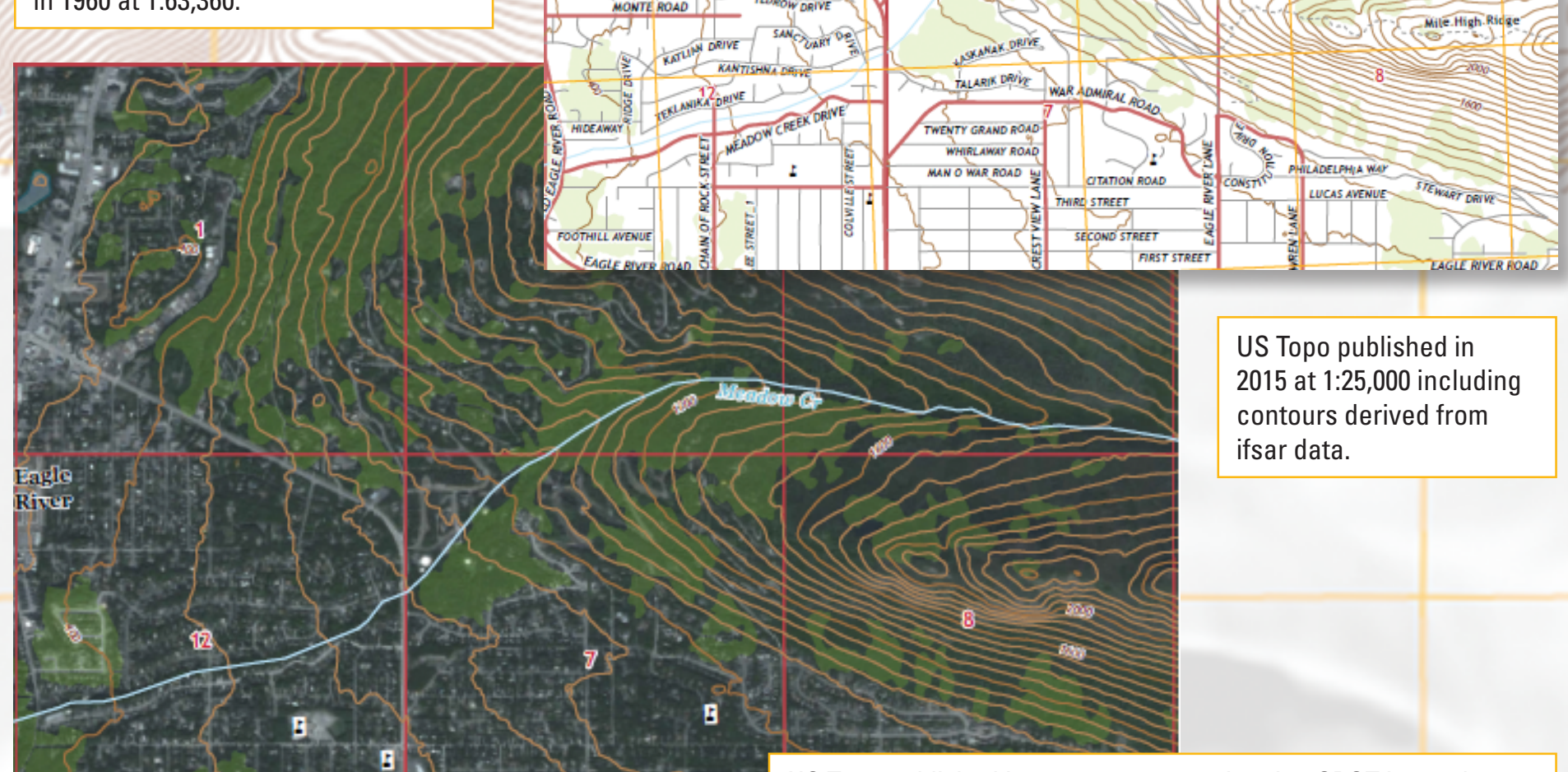

US Topo published in 2015 at 1:25,000 including contours derived from ifsar data. 


\section{Science Benefits from Updated Ifsar Data in Alaska}

Multiple State and Federal agencies are collaborating to acquire new ifsar data for the State of Alaska. The digital mapping data products created from ifsar can be used for many, diverse scientific applications.

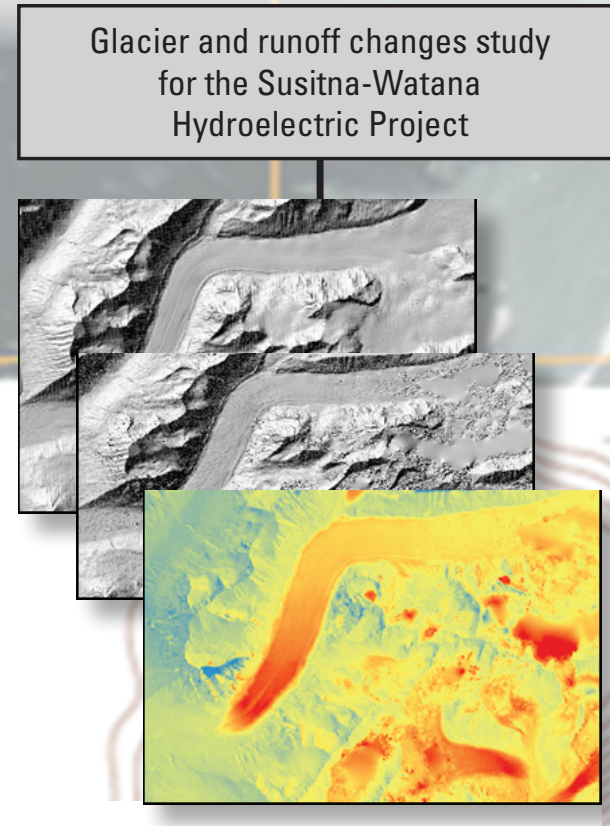

Glacier surface elevation difference map of the East Fork Glacier in the Central Alaska Range.
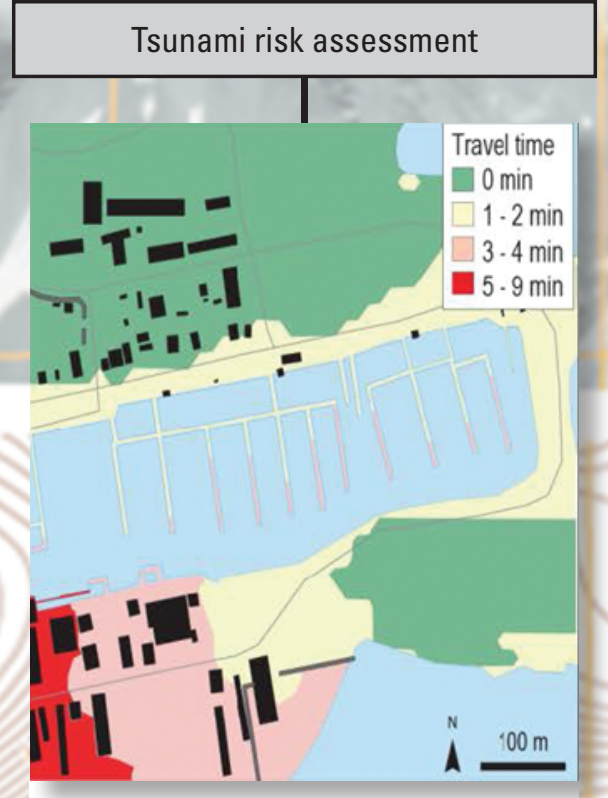

Estimated evacuation times based on inundation area calculation.

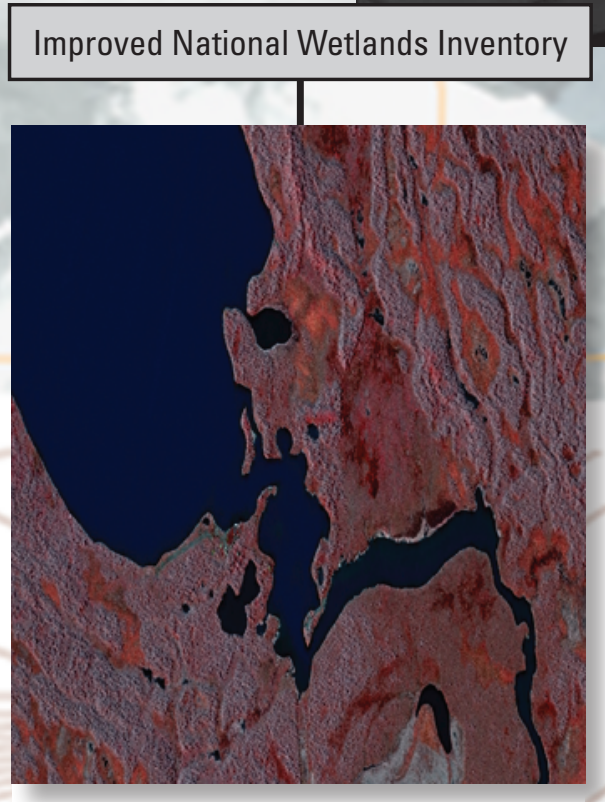

Ifsar fused with SPOT orthoimagery used to update the National Wetlands Inventory.

\section{Updating Water Information Using Ifsar Data in Alaska}

One of the scientific applications of ifsar data is the ability to improve surface water information included in the National Hydrography Dataset (NHD) and Watershed Boundary Dataset (WBD).
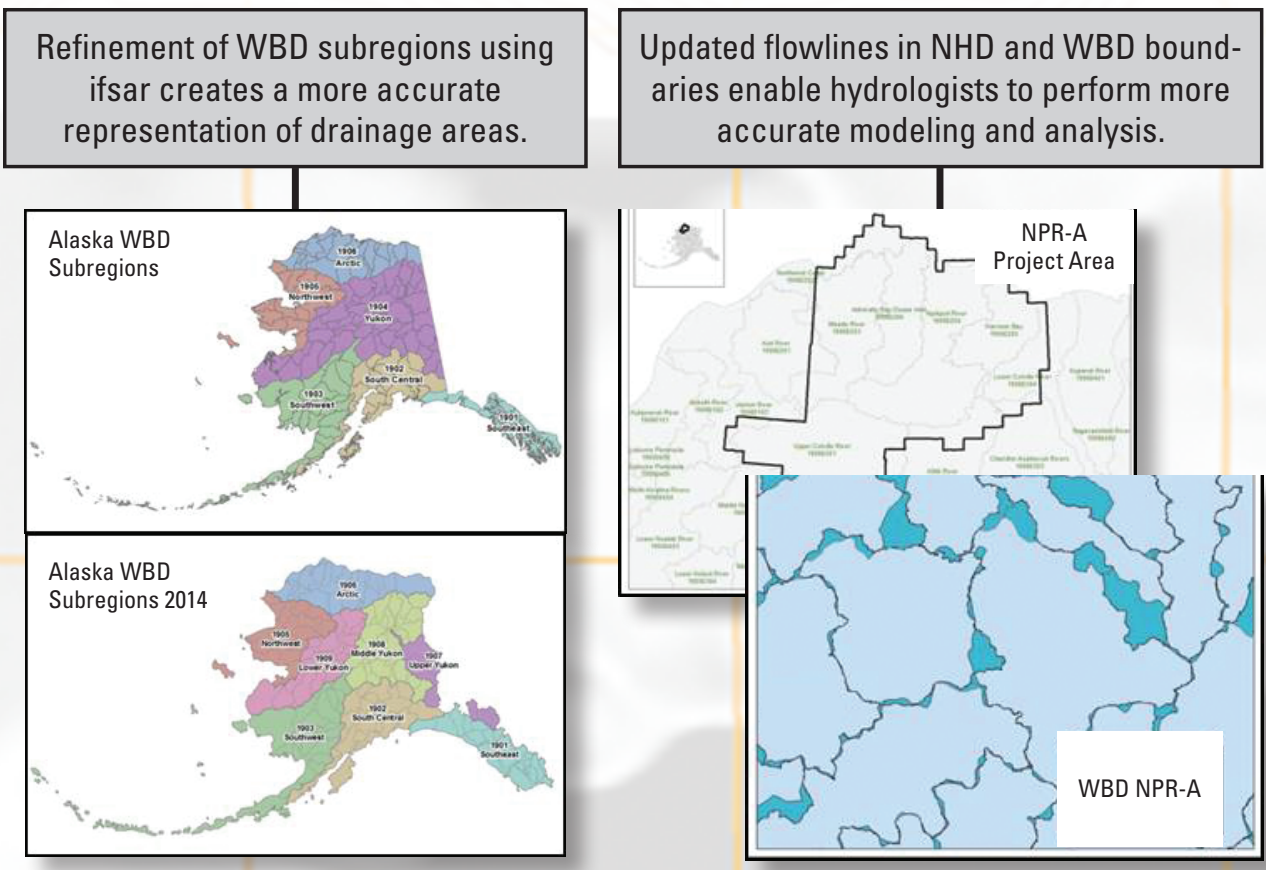

Cross-border harmonization of the WBD with Canada allows for more seamless international water resource management.

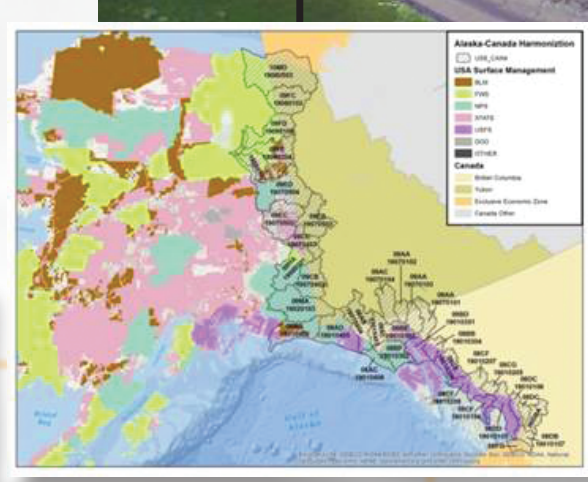

For more information: http://nationalmap.gov/alaska/ ISSN 2327-6916 (print) ISSN 2327-6932 (online) http://dx.doi.org/10.3133/fs20153051 